\title{
Liquid Biopsy in Endometrial Cancer: New Opportunities for Personalized Oncology
}

\author{
Laura Muinelo-Romay ${ }^{1}$, Carlos Casas-Arozamena ${ }^{2}$ and Miguel Abal ${ }^{2, *}$ (i) \\ 1 Liquid Biopsy Analysis Unit, Translational Medical Oncology Group (Oncomet), CIBERONC, \\ Health Research Institute of Santiago de Compostela (IDIS), University Hospital of Santiago de \\ Compostela (SERGAS), Trav. Choupana s/n, 15706 Santiago de Compostela, Spain; \\ laura.muinelo.romay@sergas.es \\ 2 Translational Medical Oncology Group (Oncomet), CIBERONC, Health Research Institute of Santiago (IDIS), \\ University Hospital of Santiago de Compostela (SERGAS), Trav. Choupana s/n, \\ 15706 Santiago de Compostela, Spain; carlos.casas_95@hotmail.es \\ * Correspondence: miguel.abal.posada@sergas.es; Tel.: +34-981-955-073
}

Received: 15 June 2018; Accepted: 2 August 2018; Published: 7 August 2018

\begin{abstract}
The identification of new molecular targets and biomarkers associated with high risk of recurrence and response to therapy represents one of the main clinical challenges in the management of advanced disease in endometrial cancer. In this sense, the field of liquid biopsy has emerged as a great revolution in oncology and is considered "the way" to reach personalised medicine. In this review, we discuss the promising but already relatively limited advances of liquid biopsy in endometrial cancer compared to other types of tumours like breast, colorectal or prostate cancer. We present recent data analysing circulating tumour material in minimally-invasive blood samples, but also in alternative forms of liquid biopsy like uterine aspirates. Proteomic and genomic studies focused on liquid-based uterine samples are resulting not only in optimal diagnostic tools but also in reliable approaches to address tumour heterogeneity. Likewise, circulating tumour cells (CTCs) and circulating tumour DNA (ctDNA) represent an opportunity for the correct stratification of patients, for the assessment of early recurrent disease or for the real-time monitoring of therapy responses. Appropriately designed studies and implementation in clinical trials will determine the value of liquid biopsy for precision oncology in endometrial cancer.
\end{abstract}

Keywords: liquid biopsy; uterine aspirate; circulating tumour cells (CTCs); circulating tumour DNA (ctDNA); exosomes

\section{Challenges in Endometrial Cancer}

Endometrial cancer (EC) is the fourth leading cancer in women from developed countries. In Europe, the number of new cases was about 100,000 in 2012, with an incidence of 13.6 per 100,000 women [1]. This tumour originates in the inner layer of the uterus when epithelial cells lining the myometrium start to proliferate abnormally. Although most ECs are diagnosed early, mainly due to symptomatic postmenopausal metrorrhagia, up to $20 \%$ of the lesions progress to a high-stage carcinoma. Unfortunately, the five-year survival in this group of women drops to $15 \%$, compared to $90 \%$ in women diagnosed with confined disease. Myometrial infiltration and the appearance of disseminated aggressive tumour cells are crucial events for prognosis and death in EC [2]. Surgery represents the primary treatment. In addition, patients with high risk of recurrence also receive adjuvant radiotherapy, together with chemotherapy that is restricted to metastatic/recurrent disease and high-grade ECs. However, traditional chemotherapy regimens are less effective in comparison with other cancers. This overview situates the clinical challenge on the identification of new molecular 
targets and biomarkers associated with a high risk of recurrence and/or with response to therapy as valuable tools to improve our management of advanced disease in endometrial cancer.

EC is classified into two distinct groups, type I and type II, which differ in molecular, clinical and histopathological characteristics. Type I tumours are low-grade and estrogen-related endometrioid carcinomas (EEC), while type II are non-endometrioid (NEEC), mainly serous and clear cell carcinomas. To date, this classification has been demonstrated to be an important predictor of survival, but also a determinant for the extent of the initial surgical procedure and subsequent use of adjuvant therapy. However, the molecular heterogeneity associated with the histological diversity of this type of cancer makes the current treatment options insufficiently personalised. To this regard, the integrated genomic, transcriptomic and proteomic characterisation of EC performed by The Cancer Genome Atlas Research Network (TCGA) revealed four groups of tumours [3]. The first group (EEC1) includes EEC with somatic inactivating mutations in POLE exonuclease and very high mutation rates (hypermutated) (7\%); it is associated with a good prognosis. The second group (EEC2) includes EEC with microsatellite instability, frequently with MLH-1 promoter hypermethylation and high mutation rates (28\%). The third group (EEC3) is composed of EEC with low copy number alterations (39\%). Importantly, both the second and third groups show similar progression-free survival rates. Finally, the fourth group (serous-like or copy-number high) (26\%) shows low mutation rate but frequent TP53 mutations. This group has worse prognosis, being predominantly composed of serous carcinomas with some sporadic cases of ECC (mainly EEC3 and some EEC1-2). The incorporation of TCGA surrogate classification into clinical practice should carry important advantages in the management of EC patients [4]. The prognostic value of TCGA in EC has been corroborated in large cohorts included in studies developed by the Vancouver and PORTEC (Post Operative Radiation Therapy in Endometrial Carcinoma) groups [5,6]. This can be especially relevant in adjuvant treatment choices for high to intermediate-risk EC patients that are likely to be impacted by the integrated molecular classification [7], while recurrent disease may continue to represent an additional challenge. Despite these stratification conditionings, and as demonstrated in the majority of solid tumours, EC shows intratumour heterogeneity with different neoplastic cell components within the same tumour. These cells have different morphologic and molecular features that may present a relevant clinical impact, especially for the assessment of prognosis and clinical management of EC patients [8]. In this sense, the use of liquid biopsies to diagnose and characterise EC can facilitate the integration of tumour heterogeneity into the therapy selection and monitoring.

\section{Liquid Biopsy}

Nowadays, research efforts are focused on the discovery of new non-invasive methods for the diagnosis and comprehension of the tumour molecular architecture in real time. In comparison with traditional biopsies, the study of the tumour material present in bodily fluids can provide valuable information for the diagnosis of tumours with low accessibility, or for a more complete overview of tumours in advanced stages where there are different tumour locations to be interrogated. Liquid biopsies also offer advantages to monitor the tumour evolution and the response to therapy with more accuracy than current clinical imaging techniques. In this sense, the field of liquid biopsy has emerged as a great revolution in oncology and is considered "the way" to reach precision medicine. In addition to blood, several other bodily fluids such as saliva, urine, cerebrospinal fluid (CSF), uterine aspirates, pleural effusions or even stool have been shown high interest as a non-invasive source of tumour-derived material [9]. This tumour circulating material is mainly composed of circulating tumour cells (CTCs), circulating tumour DNA (ctDNA), circulating tumour miRNA, proteins and exosomes [10].

The analysis of these different types of liquid biopsy has been successfully applied in oncology research during the last two decades, closely linked to the development of ultrasensitive methods for their detection. In fact, the main limitation to working with liquid biopsy is the low quantity of tumour material present in circulation. For example, in metastatic patients, the mean CTC level is $1 \mathrm{CTC} / 10^{6-8}$ 
mononuclear cells, while ctDNA is normally less than $0.01 \%$. Fortunately, nowadays we have highly sensitive techniques to tackle liquid biopsy analyses with enough guarantees [9].

CTC research is considered the start-point of the liquid biopsy field. Early in the formation and growth of a primary tumour, cells are released into the bloodstream. Several groups are studying the clinical benefit of CTC monitoring. CTCs have been validated as a prognostic marker in metastatic breast cancer and other solid tumours such as prostate, colorectal, and lung cancer, showing even more accuracy than conventional imaging methods for response evaluation. However, there are still technological challenges to use CTC monitoring to detect minimal residual disease in patients at early stages. On the other hand, the molecular characterisation of CTCs is of great value to guide the selection of targeted therapies since it allows clinicians to have a dynamic view of different molecular targets such as ERBB2, EGFR, AR or PD-L1, among others [11,12].

Despite all the studies demonstrating the relevance of CTCs for cancer management, the results from clinical trials have failed to demonstrate a clear clinical benefit. In comparison, the younger brother of CTCs, the ctDNA, has already been implemented in routine clinical practice after EMA (European Medicines Agency) approval of the EGFR mutation test (Therascreen EGFR Plasma, Qiagen) in plasma of patients with non-small cell lung cancer (NSCLC) [13]. Highly sensitive and specific methods have been developed to detect ctDNA, including beads, emulsion, amplification and magnetics based digital PCR (BEAMing) [14], safe sequencing (Safe-Seq) [15], tagged amplicon deep sequencing (TAm-Seq) [16], and digital PCR [17] to detect point mutations or whole-genome sequencing [18]. Using these technologies, several studies have demonstrated that ctDNA may be a useful tool for drug development and for the study of intratumour heterogeneity and clonal evolution in tumours such as breast, colon, melanoma and NSCLC [13]. In gynaecological tumours, and especially for ovarian cancer, TAm-Seq has demonstrated high sensitivity to detect point mutations [16].

On the other hand, the interest in characterising circulating exosomes and miRNAs is continuously increasing. These tumour entities contribute to cancer development and metastasis, and their detection in a variety of biological fluids represents a promising strategy to identify specific biomarkers with diagnostic and prognostic relevance. An additional advantage of circulating exosomes versus CTCs or ctDNA is that these extracellular vesicles can provide higher amounts of tumour material for genetic analyses. Many kits have been commercialised for improved and simplified isolation, such as ExoQuick (System Bioscience). Furthermore, tumour exosome biomarkers such as HSP60 and GPC1 have been described as valuable candidates for colorectal, pancreatic and breast cancer detection. However, these studies on exosomes and miRNA in blood are still quite exploratory and further validation in clinical studies with standardised protocols is mandatory before the routine use of these biomarkers in the clinic $[19,20]$.

\section{Liquid Biopsy in Endometrial Cancer}

Liquid biopsies will play a key role in managing EC patients in the coming years, in addition to multiple other tumour types. This includes different clinical scenarios such as early diagnosis, tumour phenotyping, therapy selection and disease monitoring in real time. Below, we provide an overview of the different forms of liquid biopsy that can be exploited in patients with endometrial cancer towards personalised medicine (Table 1, Figure 1).

\subsection{Uterine Aspirates}

In addition to peripheral blood as the prototypical form of liquid biopsy and main source of tumour material with clinical utility, the uterine aspirate represents an alternative form of liquid biopsy with high relevance in gynaecological malignancies. This is of special importance in EC diagnosis to address an increasing incidence in developed countries [1]. Risk factors for EC include age $\geq 40$ years, obesity, diabetes, hypertension, estrogen using, tamoxifen treatment, and family history of malignant tumours. Many of these factors are tightly linked to current lifestyles in developed countries. An effective screening strategy for women with high-risk factors may contribute to the early detection and 
management of EC, and a screening policy using liquid-based cytology could be considered in selected high-risk groups of patients in developed countries (Table 1). The diagnostic procedure consists of pelvic examination and transvaginal ultrasonography, followed by the histopathologic observation of an endometrial biopsy, which is preferably obtained by a minimally invasive aspiration from the uterine cavity using a Cornier pipelle (i.e., uterine aspirate or pipelle biopsy). Diagnosis is achieved by the observation of abnormal cells in the uterine aspirate, which presents high sensitivity to detect EC [21]. However, high failure rates with an average of $22 \%$ of histologically inadequate specimens have been reported, and a more invasive test such as dilatation and curettage (D\&C) or hysteroscopy must be performed, with the added risks of anesthesia, infection and perforation, and higher health care costs. There is a high concordance in molecular subtype assignment between hysterectomy specimens and diagnostic endometrial specimens as obtained by office biopsy (e.g., pipelle) or dilatation and curettage [22]. This makes liquid-based endometrial cytology, which prepares samples for cytology examination by depositing the collected sample into a preservative liquid, a useful method for detecting endometrial pathologies as a first-line approach compared to the more invasive, painful and expensive endometrial biopsy, D\&C and hysteroscopy. Cytology sampling performed by brushing the uterus cavity followed by a liquid-based smear has demonstrated an optimal diagnostic accuracy [23].

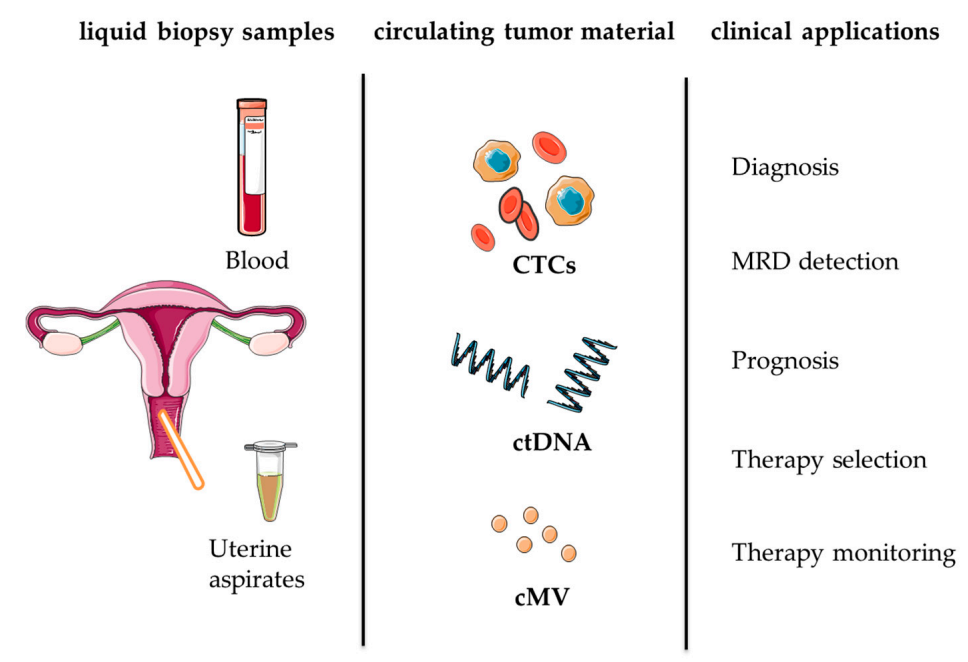

Figure 1. Liquid biopsy for personalised medicine in endometrial cancer. CTCs (circulating tumor cells), ctDNA (circulating tumor DNA), cMV (circulating microvesicles), MRD (minimal residual disease).

The endometrial fluid is a non-invasive sample which contains numerous secreted proteins representative of endometrial function and reflects the state of the endometrium. This type of liquid biopsy can result in a comprehensive catalogue of proteins of the endometrial fluid during the secretory phase of the menstrual cycle [24], but also as a promising biological fluid in which to identify potential endometrial cancer biomarkers for its early diagnosis, such as costars family protein ABRACL and phosphoglycerate mutase 2 [25]. The fluid fraction of uterine aspirates are minimally invasive samples with an important value for the screening of EC protein biomarkers, leading to uterine aspirate-based signatures to diagnose EC and classify tumours in the most prevalent histologic subtypes [26]. This will improve diagnosis and assist in the prediction of the optimal surgical treatment. In addition to proteomics in uterine aspirates as an alternative form of liquid biopsy, the potential of targeted genetic sequencing of uterine aspirates has been assessed as a pre-operative tool to obtain reliable information regarding the mutational profile of a given tumour, even in samples that are not histologically classifiable [8]. Notably, the genetic analysis of uterine aspirates captures the high intratumour genetic heterogeneity associated with endometrial cancer, solving the potential problem of incomplete genetic characterisation when a single tumour biopsy is analysed. PapSEEK, a recently developed test that interrogates for mutations in 18 genes as well as for aneuploidy after Tao and 
Pap brush, showed $81 \%$ (95\% CI, 76-84\%) of EC patients with detectable mutations, including $78 \%$ of patients with early-stage disease and $89 \%$ of the patients with late-stage disease. In addition, comparing intrauterine sampling with a Tao brush and endocervical sampling with a Pap brush, the former showed an improved detection rate of $93 \%$ of 123 (95\% CI, 87-97\%) patients with endometrial cancer. The most commonly mutated genes in both Tao and Pap brush samples were: PTEN (63\%), TP53 (42\%), PIK3CA (36\%), PIK3R1 (20\%), KRAS (17\%), CTNNB1 (15\%), FGFR2 (15\%), RNF43 (11\%), PPP2R1A (7\%), POLE (7\%), and FBXW7 (6\%), clearly representing the endometrial cancer mutational landscape [27].

Table 1. Clinical research approaches to liquid biopsy in endometrial cancer.

\begin{tabular}{|c|c|c|c|c|}
\hline Liquid Biopsy & Technology & Clinical Setting & Biomarkers & References \\
\hline \multirow[t]{2}{*}{ Uterine Aspirate } & Targeted Proteomics & Diagnosis & $\begin{array}{l}\text { ABRACL and PGAM2; KPYM, MMP9, } \\
\text { to identify the disease; CTNB1, XPO2, } \\
\text { and CAPG to discriminate between } \\
\text { endometrioid endometrial carcinomas (EEC) } \\
\text { and serous endometrial carcinoma (SEC) }\end{array}$ & {$[25,26]$} \\
\hline & Targeted Sequencing & Diagnosis & $\begin{array}{l}\text { PTEN, PIK3CA, CTNNB1, TP53, FGFR2, } \\
\text { KRAS, CDKN2A (most common mutated } \\
\text { genes in endometrial cancer (EC)) }\end{array}$ & {$[8,27]$} \\
\hline \multirow{4}{*}{$\begin{array}{l}\text { Circulating Tumour } \\
\text { Cells (CTC) }\end{array}$} & $\begin{array}{l}\text { EpCAM-Based } \\
\text { Immunoisolation } \\
\left(\text { CellSearch }^{\circledR}\right) \text { and IF }\end{array}$ & Prognosis & $\begin{array}{c}\text { CK-8, CK-18, CK-19, ETV5, NOTCH1, SNAI1, } \\
\text { TGFB1, ZEB1 and ZEB2 }\end{array}$ & [28-31] \\
\hline & $\begin{array}{c}\text { Density-based } \\
\text { Enrichment (Oncoquick) } \\
\text { and RTqPCR }\end{array}$ & Prognosis & $\begin{array}{c}\text { CCNE2, DKFZp762E1312, EMP2, MAL2, } \\
\text { PPIC, and SLC6A8 }\end{array}$ & [32] \\
\hline & $\begin{array}{l}\text { RTqPCR and } \\
\text { flow cytometry }\end{array}$ & Prognosis & $\begin{array}{l}\text { TTF-1 and the mRNA expression of: survivin, } \\
\beta \text {-catenin, miR-15a, and PTEN }\end{array}$ & [33] \\
\hline & $\begin{array}{l}\text { Size-Based Enrichment } \\
\left(\text { Metacell }{ }^{\circledR}\right) \text { and } \\
\text { Immunodetection }\end{array}$ & Prognosis & $\begin{array}{l}\text { CTCs were defined based on: (i) cell size } \\
\geq 15 \mu \mathrm{m} \text {; (ii) nuclear size } \geq 10 \mu \mathrm{m} \text { ); } \\
\text { (iii) irregularity of the nuclear contour; } \\
\text { (iv) visible cytoplasm; (v) prominent nucleoli; } \\
\text { (vi) high nuclear-cytoplasmic ratio; } \\
\text { (vii) cluster presence; (viii) mitosis presence. }\end{array}$ & [34] \\
\hline $\begin{array}{l}\text { Endothelial Progenitor } \\
\text { Cells (EPC) }\end{array}$ & Flow Cytometry & Diagnosis & VEGFR2/KDR and CD34 & [35] \\
\hline \multirow{4}{*}{$\begin{array}{l}\text { Cell Free DNA } \\
\text { (cfDNA) }\end{array}$} & PCR-RFLP & Prognosis & KRAS & [36] \\
\hline & RTqPCR & Prognosis & Alu sequences & [37] \\
\hline & Alu-RTqPCR & Prognosis & cfDNA content and integrity index & [38] \\
\hline & NGS & Diagnosis & Copy number variations (CNVs) & [39] \\
\hline $\begin{array}{l}\text { Circulating Tumour } \\
\text { DNA (ctDNA) }\end{array}$ & Droplet Digital PCR & Response to Treatment & $\begin{array}{l}\text { Various tumour-specific fusions and } \\
\text { mutations in ctDNA }\end{array}$ & [40] \\
\hline Circulating miRNA & RTqPCR & Diagnosis/Prognosis & $\begin{array}{c}\mathrm{miR}-99 \mathrm{a} / \mathrm{miR}-199 \mathrm{~b}, \mathrm{miR}-9 / \mathrm{miR}-1228 \text { and } \\
\mathrm{miR}-9 / \mathrm{miR}-92 \mathrm{a}, \mathrm{miR}-222, \mathrm{miR}-223, \mathrm{miR}-186 \\
\text { miR-204 and miR-21 }\end{array}$ & [38-41] \\
\hline
\end{tabular}

\subsection{Circulating Tumour Cells (CTCS)}

The presence of circulating tumour cells (CTCs) has been evaluated with the FDA approved technology CellSearch. The findings consistently point to a small number of high-risk EC patients presenting with EpCAM positive CTCs in circulation at the time of diagnosis, although limited cohort studies have been conducted: a study with 7\% $(n=28)$ CTC-positive grade 3 EC patients with an association between positive CTCs and both deep myometrial infiltration and positive lymph nodes has been described [28]. Similarly, 15\% $(n=40)$ CTC-positive high-risk EC patients have been observed, associated in this case with cervical involvement [29]; in addition, no significant correlation was found between CTCs and serum CA125/HE4 and no CTCs were detected after the first cycle of standard chemotherapy. The ENITEC (European Network for Individualized Treatment in EC) Consortium described a study with $22 \%(n=32)$ CTC-positive high-risk EC patients [30]. Finally, another study described $60 \%(n=30)$ CTC-positive advanced EC patients with detectable circulating tumour cells, generally associated with non-endometrioid versus endometrioid histology, tumour size $\geq 5$ versus $<5 \mathrm{~cm}$, higher-stage disease and worse survival [31]. Although the detection of CTCs in the blood might be of help to determine the potential risk of recurrence in EC patients and to assess 
the prognosis and possibly guide postoperative treatment, no conclusive information is available, thus limiting their utility in the clinical setting (Table 1).

The combination of isolated CTCs and RTqPCR of a panel of genes has also been explored in EC. Obermayr et al., performed a multimarker analysis using a panel of six genes (CCNE2, DKFZp762E1312, $E M P 2, M A L 2, P P I C$, and SLC6A8) for the detection of CTCs which positively identified $64 \%$ of a cohort of 25 EC patients [32]. Importantly, gene-expression profiling characterised a strong CTC-plasticity phenotype with stemness and epithelial-to-mesenchymal transition (EMT) features that may provide an advantage in the promotion of metastasis for CTC dissemination and homing. The in vitro recapitulation of this phenotype indicated an improved metastasis efficiency. Moreover, the CTC expression of CTNNB1, STS, GDF15, RELA, RUNX1, BRAF and PIK3CA suggested potential therapeutic targets [30]. Regarding biomarkers associated with circulating tumour cells (CTCs), the expression of thyroid transcription factor-1 (TTF-1) correlated with TNM staging, vascular infiltration, and lymphatic metastasis. Progression-free survival (PFS) and the median survival time decreased in the TTF-1-positive group compared with the TTF-1-negative group. Additionally, the recurrence rate increased in the TTF-1-positive group [33].

Finally, using size-based enrichment (MetaCell system), Kolostova et al., demonstrated the feasibility of isolating CTCs from ovarian, endometrial and cervical cancers, and culturing them in vitro for a short time [34]. More recently, and using the same enrichment strategy, peripheral blood samples from 92 patients who underwent a surgical procedure were evaluated for the presence of CTCs, showing an improved detection rate compared to previous studies. In addition, the authors claimed that endometrial CTCs were successfully cultured for further downstream functional and molecular characterisation [42].

In addition to CTCs, other circulating cells have been described as potential EC biomarkers (Table 1). Besides their role in cardiovascular diseases, circulating endothelial cells (CEC) are considered a biomarker for different neoplasms as they play a relevant role in tumour angiogenesis, which is essential for invasive tumour growth and metastasis [43]. Endothelial progenitor cell numbers (CD34, VEGFR2/KDR) in the peripheral blood of women with early endometrial carcinoma were significantly augmented compared with those of healthy control women, while circulating endothelial cell numbers (CD31, CD45) were similar in both groups [35]. By contrast, no prognostic significance or association with clinicopathological features have been demonstrated for the presence of disseminated tumour cells (DTC) in the bone marrow of endometrial carcinoma patients [44,45].

\subsection{Cell free DNA (cfDNA)}

Changes in circulating cell-free DNA (cfDNA) levels have been associated with cancer development and progression. However, very few studies have been developed for evaluating the cfDNA content in EC patients (Table 1). Dobrzycka et al., demonstrated the feasibility of cfDNA detection using the PCR-RFLP and enriched by the PCR-RFPL method in a cohort of 109 patients with EC (87 patients with type I and 22 patients with type II) [36]. In this cohort, TP53 mutations were also identified in plasma, frequently in early serous carcinomas, and a high frequency of KRAS mutations in grade 2 endometrioid tumours. This was one of the first studies focused on EC that suggested the value of cfDNA monitoring as a marker for predicting the prognosis and selecting individualised treatment regimens [36]. Tanaka et al. also evaluated the cfDNA in 15 healthy individuals, nine with benign gynaecologic diseases, and 53 with EC. They analysed Alu sequences in free DNA fragments by RTqPCR as surrogate markers and found that cfDNA levels in EC tended to be higher than in healthy and benign conditions, although there was no significant difference in cfDNA among stage or histological grade of EC, and no significant changes before and after surgery [37]. A recent report detected augmented levels of total cfDNA and mitochondrial cell-free DNA (cfmtDNA) in serum of patients with EC compared to benign lesions using a SYBR Gold assay and $\mathrm{qPCR}$, respectively. Importantly, they observed that this increase was significantly larger in high grade EC [46]. The same group also explored the cfDNA 
integrity index as a rapid and noninvasive biomarker that might provide complementary information for diagnosis, prognosis, and treatment stratification in cancer patients [38].

Recently, Zou et al., developed an algorithm called eTumorType to identify different cancer types, including 149 cervical squamous cell carcinoma and endocervical adenocarcinoma and 401 uterine corpus endometrial carcinoma [39]. This test is based on copy number variations (CNVs) of the cancer founding clone, modelling cancer hallmark-associated genes, and integrates cancer hallmark concepts and a few computational techniques. Relatively high accuracies from 0.63 to 0.92 were obtained for these gynaecologic tumours using eTumorType, indicating its value in non-invasive diagnosis [39]. More interestingly, the use of personalised ctDNA biomarkers in gynaecologic cancers including EC could demonstrate the presence of residual tumour; in addition, ctDNA predicted response to treatment in a more dynamic manner relative to currently used serum and imaging studies [40]. Patient/tumour-specific mutations were identified using whole-exome and targeted gene sequencing, and ctDNA levels were quantified using droplet digital PCR. Of particular interest, ctDNA was an independent predictor of survival. Early detection of disease persistence and/or recurrence and the ability to stratify patients in better and worse outcome groups by ctDNA surveillance may improve survival and quality of life in patients with endometrial cancer [40].

Epigenetic markers have also demonstrated great potential for the identification of different tumours. In fact, the methylation status of a number of genes has been described as an accurate tool for cancer detection. For example, SEPT9 showed value for colorectal cancer identification, while MGMT methylation detected brain tumours $[47,48]$. Margolin et al., described a specific hypermethylation at the ZNF154 CpG island in EC tissues compared to normal controls. These results in tissue were also validated in silico for blood testing [49]. Although these are promising results and methylation markers present advantages in comparison with point mutations, there is still a need for a methodological standardisation to implement these markers in clinical routine.

\subsection{Circulating Exosomes/miRNAs}

Extracellular vesicles containing proteins, lipids, and DNA/RNAs involved in intercellular communication are also considered as alternative forms of liquid biopsy [50]. Among them, exosomes (approximately $100 \mathrm{~nm}$ nanovesicles) released from endometrial epithelial cells are an important component of these interactions, as not only are they restricted to tumour cells, but endometrial cancer cells can transmit small regulatory RNAs to endometrial fibroblasts via exosomes [51]. Isolated exosome-like vesicles could become an attractive source of biomarkers, including RNA, by the analysis of the specific inner cargo by RTqPCR from uterine aspirates [52].

For diagnostic purposes, circulating miRNAs (particularly in plasma/serum) have appeared as an important source of clinical material [53]. Torres et al., studied microRNA expression in plasma samples of patients with EC for the first time [54]. They found high expression levels of miR-99a, miR-100 and miR-199b in plasma samples from patients in comparison with healthy controls. The combined analysis for plasma miR-99a/miR-199b resulted in $88 \%$ sensitivity and $93 \%$ specificity discriminating patients vs. controls, indicating a good diagnostic potential. A more recent study analysed 16 miRNAs in plasma of $34 \mathrm{EC}$ patients and 14 controls, finding miR-9/miR-1228 and miR-9/miR-92a signatures as a good diagnostic tool (Area Under Curve, AUC values 0.9) [55]. After a genome wide serum miRNA expression analysis, Jia et al., identified miR-222, miR-223, miR-186 and miR-204 up-regulation as a powerful signature for EC detection (AUC of 0.927) [56]. More recently, in a meta-analysis including EC patients, Gao et al., also demonstrated that serum miR-21 could be serve as a novel biomarker for EC. They found higher serum miR-21 levels in patients with benign lesions $(p=0.003)$ and EC $(p<0.001)$ than healthy controls, showing that EC patients also have higher expression levels $(p<0.001)$ than benign lesions [41]. Interestingly, in addition to serum and plasma samples, urinary miRNAs were also explored in patients with EC, finding a specific down-regulation of miR-106b in comparison with healthy donors [57]. All these results evidence a great potential of miRNA signatures in liquid biopsies 
as valuable information in EC, although until now there is no consistent and clinically validated signature of miRNAs for a reliable clinical management of EC patients.

\section{Conclusions}

Although liquid biopsy can be considered a reality in the clinical setting of some types of cancers, such as breast, colorectal or prostate, it remains as a promising field in gynaecological oncology. The value of liquid biopsy-related technologies in endometrial cancer, such as diagnostic/screening tools based on tumour material in uterine aspirates and as prognostic/monitoring tools based on tumour material in circulation like CTCs or ctDNA (Table 1), needs to be analytically and clinically validated in large clinical trials. Moreover, the potential combination of different and complementary types of liquid biopsy for surgery stratification and during follow-up in intermediate/high-risk and advanced EC patients might result in a comprehensive strategy targeting the identification of mutations for the evaluation of residual disease, the early detection of recurrence, the selection of personalised therapies and disease relapse associated with therapy resistance (Figure 1). These type of strategies appropriately designed and validated in clinical trials, including accurate technical and cost-effective evaluations, represent an opportunity for precision medicine in gynaecological oncology.

Funding: This research was funded by Instituto de Salud Carlos III, grants PI14/01942 and PI17/01919, co-financed by the European Regional Development Fund (FEDER).

Conflicts of Interest: The authors declare no conflict of interest. The funders had no role in the design of the study; in the collection, analyses, or interpretation of data; in the writing of the manuscript, and in the decision to publish the results.

$\begin{array}{ll}\text { Abbreviations } \\ \text { BEAMing } & \text { Beads, Emulsion, Amplification and Magnetics based digital PCR } \\ \text { CEC } & \text { Circulating Endothelial Cells } \\ \text { cMV } & \text { Circulating Microvesicles } \\ \text { CNVs } & \text { Copy Number Variation } \\ \text { CTCs } & \text { Circulating Tumour Cells } \\ \text { CK } & \text { Cytokeratin } \\ \text { ctDNA } & \text { Circulating Tumour DNA } \\ \text { DTC } & \text { Disseminated Tumour Cells } \\ \text { D\&C } & \text { Dilatation and Curettage } \\ \text { EC } & \text { Endometrial Carcinoma } \\ \text { EEC } & \text { Endometrioid Endometrial Carcinoma } \\ \text { EMA } & \text { European Medicines Agency } \\ \text { EMT } & \text { Epithelial to Mesenchymal Transition } \\ \text { EPC } & \text { Endothelial Progenitor Cells } \\ \text { NEEC } & \text { Non-Endometrioid Endometrial Carcinoma } \\ \text { NGS } & \text { Next Generation Sequencing } \\ \text { NSCLC } & \text { Non-Small Cell Lung Carcinoma } \\ \text { PFS } & \text { Progression-free Survival } \\ \text { TCGA } & \text { The Cancer Genome Atlas } \\ \text { TAm-Seq } & \text { Tagged-amplicon deep sequencing } \\ \end{array}$

\section{References}

1. Colombo, N.; Creutzberg, C.; Amant, F.; Bosse, T.; González-Martín, A.; Ledermann, J.; Marth, C.; Nout, R.; Querleu, D.; Mirza, M.R.; et al. ESMO-ESGO-ESTRO Consensus Conference on Endometrial Cancer: Diagnosis, Treatment and Follow-Up. Radiother. Oncol. 2015, 117, 559-581. [CrossRef] [PubMed]

2. Carvalho, M.J.; Laranjo, M.; Abrantes, A.M.; Torgal, I.; Botelho, M.F.; Oliveira, C.F. Clinical Translation for Endometrial Cancer Stem Cells Hypothesis. Cancer Metast. Rev. 2015, 34, 401-416. [CrossRef] [PubMed] 
3. Cancer Genome Atlas Research Network; Kandoth, C.; Schultz, N.; Cherniack, A.D.; Akbani, R.; Liu, Y.; Shen, H.; Robertson, A.G.; Pashtan, I.; Shen, R.; et al. Integrated Genomic Characterization of Endometrial Carcinoma. Nature 2013, 497, 67-73. [CrossRef] [PubMed]

4. Piulats, J.M.; Guerra, E.; Gil-Martín, M.; Roman-Canal, B.; Gatius, S.; Sanz-Pamplona, R.; Velasco, A.; Vidal, A.; Matias-Guiu, X. Molecular Approaches for Classifying Endometrial Carcinoma. Gynecol. Oncol. 2017, 145, 200-207. [CrossRef] [PubMed]

5. Talhouk, A.; McConechy, M.K.; Leung, S.; Yang, W.; Lum, A.; Senz, J.; Boyd, N.; Pike, J.; Anglesio, M.; Kwon, J.S.; et al. Confirmation of ProMisE: A Simple, Genomics-Based Clinical Classifier for Endometrial Cancer. Cancer 2017, 123, 802-813. [CrossRef] [PubMed]

6. Stelloo, E.; Bosse, T.; Nout, R.A.; MacKay, H.J.; Church, D.N.; Nijman, H.W.; Leary, A.; Edmondson, R.J.; Powell, M.E.; Crosbie, E.J.; et al. Refining Prognosis and Identifying Targetable Pathways for High-Risk Endometrial Cancer; a TransPORTEC Initiative. Mod. Pathol. 2015, 28, 836-844. [CrossRef] [PubMed]

7. McAlpine, J.; Leon-Castillo, A.; Bosse, T. The Rise of a Novel Classification System for Endometrial Carcinoma; Integration of Molecular Subclasses. J. Pathol. 2018, 244, 538-549. [CrossRef] [PubMed]

8. Mota, A.; Colás, E.; García-Sanz, P.; Campoy, I.; Rojo-Sebastián, A.; Gatius, S.; García, Á.; Chiva, L.; Alonso, S.; Gil-Moreno, A.; et al. Genetic Analysis of Uterine Aspirates Improves the Diagnostic Value and Captures the Intra-Tumor Heterogeneity of Endometrial Cancers. Mod. Pathol. 2017, 30, 134-145. [CrossRef] [PubMed]

9. Siravegna, G.; Marsoni, S.; Siena, S.; Bardelli, A. Integrating Liquid Biopsies into the Management of Cancer. Nat. Rev. Clin. Oncol. 2017, 14, 531-548. [CrossRef] [PubMed]

10. Jia, S.; Zhang, R.; Li, Z.; Li, J. Clinical and Biological Significance of Circulating Tumor Cells, Circulating Tumor DNA, and Exosomes as Biomarkers in Colorectal Cancer. Oncotarget 2017, 8, 55632-55645. [CrossRef] [PubMed]

11. Krebs, M.G.; Metcalf, R.L.; Carter, L.; Brady, G.; Blackhall, F.H.; Dive, C. Molecular Analysis of Circulating Tumour Cells-Biology and Biomarkers. Nat. Rev. Clin. Oncol. 2014, 11, 129-144. [CrossRef] [PubMed]

12. Zhang, W.; Xia, W.; Lv, Z.; Ni, C.; Xin, Y.; Yang, L. Liquid Biopsy for Cancer: Circulating Tumor Cells, Circulating Free DNA or Exosomes? Cell. Physiol. Biochem. 2017, 41, 755-768. [CrossRef] [PubMed]

13. Pasquale, R.; Fenizia, F.; Esposito Abate, R.; Sacco, A.; Esposito, C.; Forgione, L.; Rachiglio, A.M.; Bevilacqua, S.; Montanino, A.; Franco, R.; et al. Assessment of High-Sensitive Methods for the Detection of EGFR Mutations in Circulating Free Tumor DNA from NSCLC Patients. Pharmacogenomics 2015, 16, 1135-1148. [CrossRef] [PubMed]

14. Diehl, F.; Li, M.; He, Y.; Kinzler, K.W.; Vogelstein, B.; Dressman, D. BEAMing: Single-Molecule PCR on Microparticles in Water-in-Oil Emulsions. Nat. Methods 2006, 3, 551-559. [CrossRef] [PubMed]

15. Newman, A.M.; Bratman, S.V.; To, J.; Wynne, J.F.; Eclov, N.C.W.; Modlin, L.A.; Liu, C.L.; Neal, J.W.; Wakelee, H.A.; Merritt, R.E.; et al. An Ultrasensitive Method for Quantitating Circulating Tumor DNA with Broad Patient Coverage. Nat. Med. 2014, 20, 548-554. [CrossRef] [PubMed]

16. Forshew, T.; Murtaza, M.; Parkinson, C.; Gale, D.; Tsui, D.W.Y.; Kaper, F.; Dawson, S.-J.; Piskorz, A.M.; Jimenez-Linan, M.; Bentley, D.; et al. Noninvasive Identification and Monitoring of Cancer Mutations by Targeted Deep Sequencing of Plasma DNA. Sci. Transl. Med. 2012, 4, 136ra68. [CrossRef] [PubMed]

17. Taly, V.; Pekin, D.; Benhaim, L.; Kotsopoulos, S.K.; Le Corre, D.; Li, X.; Atochin, I.; Link, D.R.; Griffiths, A.D.; Pallier, K.; et al. Multiplex Picodroplet Digital PCR to Detect KRAS Mutations in Circulating DNA from the Plasma of Colorectal Cancer Patients. Clin. Chem. 2013, 59, 1722-1731. [CrossRef] [PubMed]

18. Leary, R.J.; Sausen, M.; Kinde, I.; Papadopoulos, N.; Carpten, J.D.; Craig, D.; O'Shaughnessy, J.; Kinzler, K.W.; Parmigiani, G.; Vogelstein, B.; et al. Detection of Chromosomal Alterations in the Circulation of Cancer Patients with Whole-Genome Sequencing. Sci. Transl. Med. 2012, 4, 162ra154. [CrossRef] [PubMed]

19. Melo, S.A.; Luecke, L.B.; Kahlert, C.; Fernandez, A.F.; Gammon, S.T.; Kaye, J.; LeBleu, V.S.; Mittendorf, E.A.; Weitz, J.; Rahbari, N.; et al. Glypican-1 Identifies Cancer Exosomes and Detects Early Pancreatic Cancer. Nature 2015, 523, 177-182. [CrossRef] [PubMed]

20. Caruso Bavisotto, C.; Cappello, F.; Macario, A.J.L.; Conway de Macario, E.; Logozzi, M.; Fais, S.; Campanella, C. Exosomal HSP60: A Potentially Useful Biomarker for Diagnosis, Assessing Prognosis, and Monitoring Response to Treatment. Expert Rev. Mol. Diagn. 2017, 17, 815-822. [CrossRef] [PubMed]

21. Huang, G.S.; Gebb, J.S.; Einstein, M.H.; Shahabi, S.; Novetsky, A.P.; Goldberg, G.L. Accuracy of Preoperative Endometrial Sampling for the Detection of High-Grade Endometrial Tumors. Am. J. Obstet. Gynecol. 2007, 196, 243.e1-243.e5. [CrossRef] [PubMed] 
22. Talhouk, A.; Hoang, L.N.; McConechy, M.K.; Nakonechny, Q.; Leo, J.; Cheng, A.; Leung, S.; Yang, W.; Lum, A.; Köbel, M.; et al. Molecular Classification of Endometrial Carcinoma on Diagnostic Specimens Is Highly Concordant with Final Hysterectomy: Earlier Prognostic Information to Guide Treatment. Gynecol. Oncol. 2016, 143, 46-53. [CrossRef] [PubMed]

23. Yang, X.; Ma, K.; Chen, R.; Zhao, J.; Wu, C.; Zhang, N.; Ma, X.; Dong, Y.; Zhu, S.; Liao, Q. Liquid-Based Endometrial Cytology Associated with Curettage in the Investigation of Endometrial Carcinoma in a Population of 1987 Women. Arch. Gynecol. Obstet. 2017, 296, 99-105. [CrossRef] [PubMed]

24. Casado-Vela, J.; Rodriguez-Suarez, E.; Iloro, I.; Ametzazurra, A.; Alkorta, N.; García-Velasco, J.A.; Matorras, R.; Prieto, B.; González, S.; Nagore, D.; et al. Comprehensive Proteomic Analysis of Human Endometrial Fluid Aspirate. J. Proteome Res. 2009, 8, 4622-4632. [CrossRef] [PubMed]

25. Ura, B.; Monasta, L.; Arrigoni, G.; Franchin, C.; Radillo, O.; Peterlunger, I.; Ricci, G.; Scrimin, F. A Proteomic Approach for the Identification of Biomarkers in Endometrial Cancer Uterine Aspirate. Oncotarget 2017, 8 , 109536-109545. [CrossRef] [PubMed]

26. Martinez-Garcia, E.; Lesur, A.; Devis, L.; Cabrera, S.; Matias-Guiu, X.; Hirschfeld, M.; Asberger, J.; van Oostrum, J.; Casares de Cal, M.D.L.Á.; Gómez-Tato, A.; et al. Targeted Proteomics Identifies Proteomic Signatures in Liquid Biopsies of the Endometrium to Diagnose Endometrial Cancer and Assist in the Prediction of the Optimal Surgical Treatment. Clin. Cancer Res. 2017, 23, 6458-6467. [CrossRef] [PubMed]

27. Wang, Y.; Li, L.; Douville, C.; Cohen, J.D.; Yen, T.-T.; Kinde, I.; Sundfelt, K.; Kjær, S.K.; Hruban, R.H.; Shih, I.-M.; et al. Evaluation of Liquid from the Papanicolaou Test and Other Liquid Biopsies for the Detection of Endometrial and Ovarian Cancers. Sci. Transl. Med. 2018, 10. [CrossRef] [PubMed]

28. Bogani, G.; Liu, M.C.; Dowdy, S.C.; Cliby, W.A.; Kerr, S.E.; Kalli, K.R.; Kipp, B.R.; Halling, K.C.; Campion, M.B.; Mariani, A. Detection of Circulating Tumor Cells in High-Risk Endometrial Cancer. Anticancer Res. 2015, 35, 683-687. [PubMed]

29. Ni, T.; Sun, X.; Shan, B.; Wang, J.; Liu, Y.; Gu, S.-L.; Wang, Y.-D. Detection of Circulating Tumour Cells May Add Value in Endometrial Cancer Management. Eur. J. Obstet. Gynecol. Reprod. Biol. 2016, 207, 1-4. [CrossRef] [PubMed]

30. Alonso-Alconada, L.; Muinelo-Romay, L.; Madissoo, K.; Diaz-Lopez, A.; Krakstad, C.; Trovik, J.; Wik, E.; Hapangama, D.; Coenegrachts, L.; Cano, A.; et al. Molecular Profiling of Circulating Tumor Cells Links Plasticity to the Metastatic Process in Endometrial Cancer. Mol. Cancer 2014, 13, 223. [CrossRef] [PubMed]

31. Lemech, C.R.; Ensell, L.; Paterson, J.C.; Eminowicz, G.; Lowe, H.; Arora, R.; Arkenau, H.-T.; Widschwendter, M.; MacDonald, N.; Olaitan, A.; et al. Enumeration and Molecular Characterisation of Circulating Tumour Cells in Endometrial Cancer. Oncology 2016, 91, 48-54. [CrossRef] [PubMed]

32. Obermayr, E.; Sanchez-Cabo, F.; Tea, M.-K.M.; Singer, C.F.; Krainer, M.; Fischer, M.B.; Sehouli, J.; Reinthaller, A.; Horvat, R.; Heinze, G.; et al. Assessment of a Six Gene Panel for the Molecular Detection of Circulating Tumor Cells in the Blood of Female Cancer Patients. BMC Cancer 2010, 10, 666. [CrossRef] [PubMed]

33. Zhang, Y.; Qu, X.; Qu, P.P. Value of Circulating Tumor Cells Positive for Thyroid Transcription Factor-1 (TTF-1) to Predict Recurrence and Survival Rates for Endometrial Carcinoma. J. Buon. 2016, 21, 1491-1495. [PubMed]

34. Kolostova, K.; Spicka, J.; Matkowski, R.; Bobek, V. Isolation, Primary Culture, Morphological and Molecular Characterization of Circulating Tumor Cells in Gynecological Cancers. Am. J. Transl. Res. 2015, 7, 1203-1213. [PubMed]

35. Paprocka, M.; Kieda, C.; Kantor, A.; Bielawska-Pohl, A.; Dus, D.; Czekanski, A.; Heimrath, J. Increased Endothelial Progenitor Cell Number in Early Stage of Endometrial Cancer. Int. J. Gynecol. Cancer 2017, 27, 947-952. [CrossRef] [PubMed]

36. Dobrzycka, B.; Terlikowski, S.J.; Mazurek, A.; Kowalczuk, O.; Niklinska, W.; Chyczewski, L.; Kulikowski, M. Circulating Free DNA, P53 Antibody and Mutations of KRAS Gene in Endometrial Cancer. Int. J. Cancer 2010, 127, 612-621. [CrossRef] [PubMed]

37. Tanaka, H.; Tsuda, H.; Nishimura, S.; Nomura, H.; Kataoka, F.; Chiyoda, T.; Tanaka, K.; Iguchi, Y.; Susumu, N.; Aoki, D. Role of Circulating Free Alu DNA in Endometrial Cancer. Int. J. Gynecol. Cancer 2012, 22, 82-86. [CrossRef] [PubMed] 
38. Vizza, E.; Corrado, G.; De Angeli, M.; Carosi, M.; Mancini, E.; Baiocco, E.; Chiofalo, B.; Patrizi, L.; Zampa, A.; Piaggio, G.; et al. Serum DNA Integrity Index as a Potential Molecular Biomarker in Endometrial Cancer. J. Exp. Clin. Cancer Res. 2018, 37, 16. [CrossRef] [PubMed]

39. Zou, J.; Wang, E. ETumorType, An Algorithm of Discriminating Cancer Types for Circulating Tumor Cells or Cell-Free DNAs in Blood. Genomics. Proteom. Bioinform. 2017, 15, 130-140. [CrossRef]

40. Pereira, E.; Camacho-Vanegas, O.; Anand, S.; Sebra, R.; Catalina Camacho, S.; Garnar-Wortzel, L.; Nair, N.; Moshier, E.; Wooten, M.; Uzilov, A.; et al. Personalized Circulating Tumor DNA Biomarkers Dynamically Predict Treatment Response and Survival in Gynecologic Cancers. PLoS ONE 2015, 10, e0145754. [CrossRef] [PubMed]

41. Gao, Y.; Dai, M.; Liu, H.; He, W.; Lin, S.; Yuan, T.; Chen, H.; Dai, S. Diagnostic Value of Circulating MiR-21: An Update Meta-Analysis in Various Cancers and Validation in Endometrial Cancer. Oncotarget 2016, 7, 68894-68908. [CrossRef] [PubMed]

42. Kiss, I.; Kolostova, K.; Matkowski, R.; Jędryka, M.; Czekański, A.; Pavlasek, J.; Bobek, V. Correlation Between Disease Stage and the Presence of Viable Circulating Tumor Cells in Endometrial Cancer. Anticancer Res. 2018, 38, 2983-2987. [CrossRef] [PubMed]

43. Folkman, J. Role of Angiogenesis in Tumor Growth and Metastasis. Semin. Oncol. 2002, 29 (Suppl. 16), 15-18. [CrossRef] [PubMed]

44. Banys, M.; Solomayer, E.-F.; Becker, S.; Krawczyk, N.; Gardanis, K.; Staebler, A.; Neubauer, H.; Wallwiener, D.; Fehm, T. Disseminated Tumor Cells in Bone Marrow May Affect Prognosis of Patients with Gynecologic Malignancies. Int. J. Gynecol. Cancer 2009, 19, 948-952. [CrossRef] [PubMed]

45. Kommoss, S.; Hartkopf, A.D.; Krämer, B.; Bunz, A.-K.; Grevenkamp, F.; Kommoss, F.; Pasternak, J.; Arbabi, S.M.; Wallwiener, M.; Staebler, A.; et al. Disseminated Tumor Cells Are Not Associated with Established Risk Factors, L1CAM Immunoreactivity and Outcome in Endometrial Carcinoma. J. Cancer Res. Clin. Oncol. 2017, 143, 2183-2188. [CrossRef] [PubMed]

46. Cicchillitti, L.; Corrado, G.; De Angeli, M.; Mancini, E.; Baiocco, E.; Patrizi, L.; Zampa, A.; Merola, R.; Martayan, A.; Conti, L.; et al. Circulating Cell-Free DNA Content as Blood Based Biomarker in Endometrial Cancer. Oncotarget 2017, 8, 115230-115243. [CrossRef] [PubMed]

47. Li, Z.-C.; Bai, H.; Sun, Q.; Li, Q.; Liu, L.; Zou, Y.; Chen, Y.; Liang, C.; Zheng, H. Multiregional Radiomics Features from Multiparametric MRI for Prediction of MGMT Methylation Status in Glioblastoma Multiforme: A Multicentre Study. Eur. Radiol. 2018. [CrossRef] [PubMed]

48. Behrouz Sharif, S.; Hashemzadeh, S.; Mousavi Ardehaie, R.; Eftekharsadat, A.; Ghojazadeh, M.; Mehrtash, A.H.; Estiar, M.A.; Teimoori-Toolabi, L.; Sakhinia, E. Detection of Aberrant Methylated SEPT9 and NTRK3 Genes in Sporadic Colorectal Cancer Patients as a Potential Diagnostic Biomarker. Oncol. Lett. 2016, 12, 5335-5343. [CrossRef] [PubMed]

49. Margolin, G.; Petrykowska, H.M.; Jameel, N.; Bell, D.W.; Young, A.C.; Elnitski, L. Robust Detection of DNA Hypermethylation of ZNF154 as a Pan-Cancer Locus with in Silico Modeling for Blood-Based Diagnostic Development. J. Mol. Diagn. 2016, 18, 283-298. [CrossRef] [PubMed]

50. Van Niel, G.; D'Angelo, G.; Raposo, G. Shedding Light on the Cell Biology of Extracellular Vesicles. Nat. Rev. Mol. Cell Biol. 2018, 19, 213-228. [CrossRef] [PubMed]

51. Maida, Y.; Takakura, M.; Nishiuchi, T.; Yoshimoto, T.; Kyo, S. Exosomal Transfer of Functional Small RNAs Mediates Cancer-Stroma Communication in Human Endometrium. Cancer Med. 2016, 5, 304-314. [CrossRef] [PubMed]

52. Campoy, I.; Lanau, L.; Altadill, T.; Sequeiros, T.; Cabrera, S.; Cubo-Abert, M.; Pérez-Benavente, A.; Garcia, A.; Borrós, S.; Santamaria, A.; et al. Exosome-like Vesicles in Uterine Aspirates: A Comparison of UltracentrifugationBased Isolation Protocols. J. Transl. Med. 2016, 14, 180. [CrossRef] [PubMed]

53. Zen, K.; Zhang, C.-Y. Circulating MicroRNAs: A Novel Class of Biomarkers to Diagnose and Monitor Human Cancers. Med. Res. Rev. 2012, 32, 326-348. [CrossRef] [PubMed]

54. Torres, A.; Torres, K.; Pesci, A.; Ceccaroni, M.; Paszkowski, T.; Cassandrini, P.; Zamboni, G.; Maciejewski, R. Deregulation of MiR-100, MiR-99a and MiR-199b in Tissues and Plasma Coexists with Increased Expression of MTOR Kinase in Endometrioid Endometrial Carcinoma. BMC Cancer 2012, 12, 369. [CrossRef] [PubMed]

55. Torres, A.; Torres, K.; Pesci, A.; Ceccaroni, M.; Paszkowski, T.; Cassandrini, P.; Zamboni, G.; Maciejewski, R. Diagnostic and Prognostic Significance of MiRNA Signatures in Tissues and Plasma of Endometrioid Endometrial Carcinoma Patients. Int. J. Cancer 2013, 132, 1633-1645. [CrossRef] [PubMed] 
56. Jia, W.; Wu, Y.; Zhang, Q.; Gao, G.; Zhang, C.; Xiang, Y. Identification of Four Serum MicroRNAs from a Genome-Wide Serum MicroRNA Expression Profile as Potential Non-Invasive Biomarkers for Endometrioid Endometrial Cancer. Oncol. Lett. 2013, 6, 261-267. [CrossRef] [PubMed]

57. Záveský, L.; Jandáková, E.; Turyna, R.; Langmeierová, L.; Weinberger, V.; Záveská Drábková, L.; Hůlková, M.; Hořínek, A.; Dušková, D.; Feyereisl, J.; et al. Evaluation of Cell-Free Urine MicroRNAs Expression for the Use in Diagnosis of Ovarian and Endometrial Cancers. A Pilot Study. Pathol. Oncol. Res. 2015, 21, 1027-1035. [CrossRef] [PubMed]

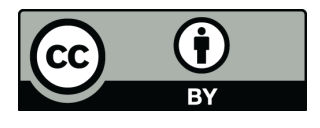

(c) 2018 by the authors. Licensee MDPI, Basel, Switzerland. This article is an open access article distributed under the terms and conditions of the Creative Commons Attribution (CC BY) license (http:/ / creativecommons.org/licenses/by/4.0/). 